\title{
Reseña de Palabras en contexto. \\ Pragmática y otras teorías del significado, de Graciela Reyes
}

\author{
ENRIQUe del Teso Martín \\ Universidad de Oviedo \\ eteso@uniovi.es \\ ORCID iD: 0000-0002-5735-2774
}

Recibida / Received: I 2-III-20I9

Aceptada / Accepted: 20-III-20I9

Graciela Reyes (201 8): Palabras en contexto. Pragmática y otras teorías del signifcado, Madrid: Arco/Libros [46o pp.]. ISBN: 978-84-7635-972-3.

T a pragmática es un río de curso rápido y con afluentes múltiples que hacen el Laudal desigual y con remolinos. En la pragmática desembocan ciertas líneas de filosofía, de ciencia cognitiva y de lingüística. Es el territorio en el que el lenguaje, y 
con él la lingüística, se encuentra con lo que está fuera de él: la situación en que se habla, la conducta de los hablantes, sus conocimientos, expectativas y maneras de razonar. El contexto es un factor que revoloteó en nuestro sentido común y en la formalidad de los trabajos gramaticales desde siempre. Pero se manejó de una manera intuitiva. Graciela Reyes dice acertadamente que el contexto siempre pareció una especie de deus ex machina, una intervención exterior no necesitada de justificación que rellena sin explicación todo lo que sobresale de las explicaciones metódicas y formales. La descripción lingüística no agota todo lo que sabemos que sucede cuando el hablante habla y entiende enunciados. Las palabras suelen decir algo más o algo distinto de lo que dice el diccionario, y sin embargo intuimos que los lexicógrafos hacen bien su trabajo y los diccionarios expresan el significado cierto de las palabras. Sabemos que las mismas palabras pueden transmitir ideas muy distintas, a veces sin vínculo lógico aparente con su significado: — ¿Ves algo a Elena? -(Con brusquedad) Son ya las doce y media. La frase Son ya las doce y media comunica que el emisor no quiere hablar de Elena, algo que no tiene nada que ver con el significado de sus palabras y ninguna concreción posible de ellas. En estos y muchos otros casos, aparece ese deus ex machina que es el contexto. El contexto es la chistera del mago de la que sale todo lo que haga falta.

La cuestión es que la gramática nos enfrenta con la maquinaria interna de la lengua y, de manera variable según escuelas, con el asiento cerebral que gobierna esa maquinaria. Es un desafío con muchos frentes, pero no con todos. No nos enfrenta con el conocimiento del mundo de los hablantes, con la parte de ese conocimiento que tienen activa cuando hablan y que está funcionando justo en el momento en que lo hacen, con su razonamiento espontáneo y formal, con las expectativas y presunciones con que proyectan ese razonamiento sobre las señales que reciben y con la metarrepresentación cognitiva que los hablantes hacen de las representaciones cognitivas activas de sus interlocutores. La manera en que todo esto afecta a cómo elegimos nuestras palabras y enunciados, cómo anticipamos las pautas de interpretación de nuestro interlocutor y cómo intervienen en la interpretación de las palabras y señales que nos llegan es la sustancia de la pragmática. Y es el tipo de investigación que nos mete de lleno en la masa nebulosa y mágica del contexto y nos obliga a conformarlo como entidad teórica dentro de un discurso científico.

La pragmática, entonces, amplía los estudios del lenguaje, pero también introduce en esos estudios métodos y herramientas distintas, cuyo acoplamiento con las existentes presenta problemas y soluciones divergentes. Incluso por la variedad de sus nutrientes llega al lenguaje con diferencias internas. $Y$ a la vez no es tan raro que gramáticos con métodos irreconciliables se encuentren en razonable sintonía cuando llegan a cierta fase del estudio de la interpretación en la estela de Grice. Todo esto 
hace útil y necesaria una recopilación ordenada y competente de la agenda de la pragmática y un ordenamiento claro de sus temas. Es el grueso de lo que nos ofrece Graciela Reyes en su libro Palabras en contexto. Pragmática y otras teorías del significado, que publica Arco/Libros. No es una introducción a la pragmática ni un resumen de escuelas o tendencias. Es lo que acabamos de indicar: una extracción de los temas que la conforman, de su tratamiento y de las controversias o cuestiones abiertas que plantean. Tampoco es enteramente un libro de pragmática. Es un libro sobre lo que las palabras y enunciados significan y lo que comunican. Pero, como la autora señala en el prólogo, eso hace que la pragmática sea la mayor parte de la sustancia del libro.

Graciela Reyes toma una decisión afortunada presentando los temas principales que configuran la significación y la pragmática de forma alfabetizada y autónoma, en lugar de intentar que la sucesión exprese algún tipo de orden orgánico. Esto hace que sea una obra ordenada para ser leída como un libro convencional, pero también que pueda ser manejada como una pequeña enciclopedia de consulta y poder ir directamente a los temas que nos ocupan o sobre los que queremos aclaraciones directamente. Creo que, entre las obras alfabetizadas, acaban siendo más provechosas las que tienen relativamente pocos artículos, con amplio desarrollo de cada uno de ellos e índices generosos con muchas remisiones, que las que se organizan con muchos artículos y poco texto en cada uno. Las primeras son un conjunto de pequeños tratados estructurados que asientan bien el conocimiento organizado. Si los índices son eficaces, aunque el número de artículos sea bajo, la cantidad de términos que se pueden consultar y aclarar seguirá siendo numerosa. Las segundas, sin embargo, con frecuencia obligan a emigrar de un artículo a otro y, tras haber consultado una docena, cuesta organizar de manera ordenada un tema por lo sincopado de su lectura. Como ejemplo positivo del primer tipo, podríamos recordar el Diccionario Oxford de la mente (Gregory I995 [1987]). Como ejemplo del segundo tipo, mencionaremos el robusto Diccionario de Filosofia de Ferrater Mora (I979 [194I]), que, a pesar de su evidente altura, es de consulta farragosa. Graciela Reyes nos da las dos cosas de la mejor manera posible. El libro en sí tiene el formato de diccionario enciclopédico del primer tipo. Pero tiene un glosario al final que hace a la vez de diccionario del segundo tipo (muchos artículos, poco texto en cada artículo) y de índice analítico con el que podemos remitir cada concepto a los artículos más extensos que configuran el grueso del libro. El sistema de diacríticos que maneja hace que podamos pasar de un artículo a otro, al glosario o a la inversa con fluidez. La organización por ello es inmejorable.

Nada de esto serviría si los temas elegidos y alfabetizados en la parte general no fueran los que interesan o su desarrollo fuera banal. Los temas van desde los más 
obvios de un libro de pragmática (implicaturas, presuposiciones, polifonía...) hasta los que marcan las tendencias más actuales (accesibilidad, elementos procedimentales, subdeterminación semántica...). Y el desarrollo es verdaderamente notable. En cada artículo aparecen bien ordenados y representados los autores y teorías relevantes, de manera accesible y a la vez rigurosa. Algunos representan un desafío complicado. Por ejemplo, el artículo "Minimalismo", donde tiene que exponer el bloque de teorías semánticas que vinculan de manera más estricta el significado a la gramática y las teorías incompatibles con tales modelos, se desarrolla en menos de veinte páginas, suficientemente completo y ordenado y sin demasiadas remisiones hacia el exterior que hagan su lectura tortuosa. Un verdadero ejemplo de síntesis, claridad y rigor.

En general, el libro será útil para lectores con conocimientos avanzados de pragmática y semántica, porque la condensación de los temas a base de pequeños tratados ayudará a poner orden en sus conocimientos y a ampliarlos también ordenadamente. No resultará excesivamente escolar ni simple para el lector avanzado. Pero también es un libro muy adecuado para estudiantes y lectores menos especializados. Lógicamente no puede ser la primera lectura que se haga de pragmática y significado. Es un libro alfabetizado, los capítulos no son las partes en que se organiza una estructura general. Para iniciarse desde cero debe empezarse por un libro de introducción a la pragmática. Pero a partir de ahí el desarrollo de cada tema está expuesto con claridad, con indicaciones precisas de las fuentes para profundizar y sin exigir un bagaje previo que no sea el de iniciación.

Por mencionar alguna discrepancia menor, podría haberse aconsejado a la autora un título distinto. Palabras en contexto puede ser cualquier cosa. La idea de diccionario enciclopédico expresada en el título indicaría con más claridad el tipo de obra que se ofrece. Y hay algún descuido también menor. Se cita, por ejemplo, un trabajo de David Kaplan (1989) que no figura en la bibliografía. Pero salvo cosas de poca monta, es de verdadero interés leer este libro de manera convencional, salteada u ocasional, según necesidades. Está muy bien documentada, sintetizada y estructurada una parte de los estudios del lenguaje apasionante pero propensa a extenderse sin orillas y a diluirse sin control en los exteriores del lenguaje y de la ciencia.

\section{REFERENCIAS BIBLIOGRÁFICAS}

FERrATER MORA, José (I979 [I94I]): Diccionario de filosofía, Madrid: Alianza. 4 vols.

Gregory, Richard L. (ed.) (1995 [1987]): Diccionario Oxford de la mente (trad. Irene Cifuentes de Castro y Carmen Sigüenza Pinilla), Madrid: Alianza. 